\title{
Gradhiva
}

\section{Margarita Xanthakou, Identités en souffrance. Une ethnologie de la Grèce}

Paris, Odile Jacob, 2007, 276 p.

\section{Carmen Bernand}

\section{OpenEdition}

\section{Journals}

Édition électronique

URL : http://journals.openedition.org/gradhiva/1158

DOI : 10.4000/gradhiva. 1158

ISSN : 1760-849X

\section{Éditeur}

Musée du quai Branly Jacques Chirac

Édition imprimée

Date de publication : 15 mai 2008

Pagination : 172

ISBN : 978-2-915133-86-8

ISSN : 0764-8928

\section{Référence électronique}

Carmen Bernand, « Margarita Xanthakou, Identités en souffrance. Une ethnologie de la Grèce », Gradhiva [En ligne], 7| 2008, mis en ligne le 10 décembre 2008, consulté le 21 septembre 2020. URL : http:// journals.openedition.org/gradhiva/1158; DOI : https://doi.org/10.4000/gradhiva.1158

Ce document a été généré automatiquement le 21 septembre 2020.

(c) musée du quai Branly 


\section{Margarita Xanthakou, Identités en souffrance. Une ethnologie de la Grèce}

Paris, Odile Jacob, 2007, 276 p.

\section{Carmen Bernand}

\section{RÉFÉRENCE}

Margarita Xanthakou, Identités en souffrance. Une ethnologie de la Grèce. Paris, Odile Jacob, $2007,276 \mathrm{p}$.

1 La péninsule du Magne, qui s'étire entre la Méssenie et la Laconie, au sud du Péloponnèse et en direction de Cythère (berceau d'Aphrodite), est restée jusqu'à une époque récente en marge du flux touristique et des études ethnologiques, malgré l'intérêt historique et anthropologique de cette contrée, dominée par le relief imposant du Taygète et caractérisée par les imposantes tours de pierre, à la fois défensives et emblématiques, que ses habitants ont érigées au cours des siècles. Margarita Xanthakou, auteur de plusieurs ouvrages sur la Grèce, est une des rares ethnologues, sinon la seule, à s'être aventurée depuis les années 1970 dans cette terre apparemment hostile, pour y recueillir une magnifique moisson de récits et de données ethnographiques, dont la portée dépasse de beaucoup le cadre de la discipline et touche également la psychanalyse et la littérature. Avec ce dernier livre, l'auteur nous révèle des histoires sidérantes, tissées d'incestes multiples, de haines séculaires, de vengeances et de comportements autodestructifs, qui ne laissent aucun lecteur indifférent, même si elles sont racontées avec la sobriété qui sied à la femme de science. Margarita Xanthakou nous livre dix tranches de vie en respectant l'ordre de la narration qui lui fut faite, avec les allusions, les silences et les incohérences éventuelles. Nous sommes là dans la singularité même et pourtant l'auteur réussit à éclairer les matériaux à la lumière des théories anthropologiques, en se fondant sur les travaux de Françoise Héritier sur les substances corporelles et "l'inceste de deuxième type ». L'analyse suit le récit sans qu'il y ait surinterprétation, puisque les mots entendus 
disent sans ambigüité la crainte de la "souillure ", de l'identique (deux sœurs, deux amies comme des jumelles, deux belles-sœurs, etc.) et du mélange des "odeurs »: "J'évitais de les embrasser par peur de sentir les odeurs de l'une sur l'autre», dit Thémis, violé par son oncle maternel, comme sa mère et sa sœur, auxquelles il se réfère. Frosso et Stela, deux sœurs qui couchent avec le même homme, ont « la même odeur ».

2 Les Maniotes sont obsédés par le sang, qui est celui transmis par le père, et l'honneur qui lui est lié, caractéristique qui avait déjà frappé le voyageur Eugène Yemeniz, vers le milieu du XIX ${ }^{\mathrm{e}}$ siècle, et avant lui les Européens qui visitèrent le Magne un siècle plus tôt. "Tout pour le sang, pour ceux qui sont du même sang, fussent-ils des parents éloignés. Tu entends, mon fils ", disait la vieille, « pour les hommes de ton sang tu seras une arme, et pour les femmes, un frère ». Ces paroles, glanées dans un texte de Yorgos Ftéris, résument bien la force du lignage patrilinéaire ${ }^{1}$. Nous sommes donc en présence d'un phénomène qui se déploie dans la longue durée et qui se dévoile à Margarita Xanthakou au fil des années jusqu'à ce début du xxI siècle où les migrations, le tourisme et la modernité semblent lui asséner (mais peut-on en être sûrs ?) un coup mortel. Les témoignages recueillis portent la trace de la guerre civile, des affrontements fratricides entre partisans et miliciens et surtout du vide créé par l'émigration massive en Amérique et en Australie. Les récits contenus dans ce livre sont donc les derniers avatars d'une coutume ancestrale, le reflet crépusculaire d'un système lignager qui fit de la résistance à l'occupant la raison de son existence. Chacune des histoires racontées par Margarita Xanthakou sonne comme un moiroloi (chant rituel funèbre) pour un ordre agonisant.

3 Raconter chaque cas excéderait les limites d'un compte rendu et inciterait les lecteurs à s'en tenir au résumé, plutôt qu'à plonger dans un livre envoûtant et dérangeant. Disons seulement que les divers personnages de cet ouvrage se débattent dans un dilemme insoluble: pour exister il faut fonder une famille, mais tout mariage implique une exogamie que l'obsession du sang patrilinéaire récuse. Une femme sans protection masculine a peine à survivre mais, inversement, le mariage l'enlève à son groupe agnatique et la place en situation de dépendance extrême vis-à-vis de sa belle-famille. Sans compter que le mariage d'une fille suppose une dot que beaucoup de pères rechignent à accorder. La famille idéale serait celle constituées par l'union «létale " entre un frère et une sœur, d'où les incestes réels et fantasmés, qui n'épargnent pas la mère. De ces unions interdites, souvent provoquées par un viol, les filles et les garçons en sortent meurtris, voués au suicide ou à la mort sociale, refusant de se perpétuer pour briser le souvenir des parents abusifs. Identités lignagères, identités personnelles, identités de genre apparaissent ici dans leur dimension excessive et explosive, comme si le rétrecissement du groupe villageois avait pour effet une exacerbation des passions. Si l'analyse ethnologique que Margarita Xanthakou fait de cette violence parait tout à fait convaincante, j'ajouterai pour ma part que cet ouvrage nous plonge dans l'essence même du tragique, inventé par des Grecs il y a vingt-cinq siècles. "C'était sa moira, son destin ", explique-t-on en parlant d'une petite fille qui a survécu à l'incendie criminel de sa maison, où tous les siens ont péri. "J'ai tué ma sœur et j'ai blessé ma mère au ventre. Je ne l'ai pas fait exprès. Je ne sais pas comment c'est arrivé », raconte Kostas. L'inéluctable destin contre lequel toute révolte est vaine, celui qui détruit les Atrides, ๔Edipe et Jocaste, et qui résulte de la cruauté amusée des dieux, enchaîne Antigone et 
Électre à Aliki, Ismina, Thémis ou Katina, des familles maudites par l'attrait irrésistible et fatal du Même.

\section{NOTES}

1. Yorgos Ftéris, "Petrakas et la mort ", écrit en 1979 et reproduit dans Desmos, Librairie Héllénique, $n^{\circ}$ 23/24, consacré au "Magne, la Terre, les Hommes », 2006. On y trouvera également, parmi d'autres textes, celui d'Eugène Yemeniz, un recueil de miroloïa et un article d'Isabelle Tloupas sur les voyageurs étrangers.

\section{AUTEURS}

\section{CARMEN BERNAND}

Carmen.Bernand@wanadoo.fr 